\title{
Four Osteopoikilosis cases detected in a family
}

\author{
Semra Aytürk ${ }^{1}$, Ahmet Bilal Genç ${ }^{2}$, Selçuk Yaylacı ${ }^{2}$, Serdar Savas Gül ${ }^{3}$, Ali Tamer ${ }^{2}$, Mehmet Çelik ${ }^{2}$ \\ Trakya University Faculty of Medicine, Department of Endocrinology and Metabolism ${ }^{1}$ \\ Sakarya Education and Research Hospital,Department of Internal Medicine ${ }^{2}$ \\ Sakarya Education and Research Hospital,Department of Nuclear Medicine ${ }^{3}$
}

Introduction: Osteopoikilosis (OPK) is a rare benign sclerotic bone dysplasia. It is inherited in an autosomal dominant pattern. There is no exact evidence of its etiology and pathogenesis. Usually, it is an asymptomatic disease and the diagnosis is made incidentally from radiographs which show multiple, small, well-defined, variably shaped and widely distributed sclerotic areas over the skeleton. We report a family with OPK.

Cases: A 22 years old woman was admitted to outpatient clinic with complaints of right hip pain and fatigue for 2 years. Clinical examination was unremarkable. The patient did not have any other co-morbidity. Her laboratory and biochemical parameters were within normal limits. Numerous small round, symmetric sclerotic bone foci were detected at her pelvic radiographs. Similar lesions involving femoral head, acetabulum, sacroiliac joints, distal femur, proximal tibia as well as carpal and metacarpal bones were noted on detailed skeletal survey of the patient. Bone scintigraphy for whole body with Tc-99m was normal. Because of the radiological findings are diagnostic for OPK, family members were screened. We learned that the patient's mother and father had died. Four asymptomatic siblings were examined and three of them ( 2 male and 1 female) were found to have OPK. A follow-up program was made for them.

Conclusion: This disorder does not require any treatment and its complications are rare. However, there may be rarely associated bone tumors (such as osteosarcoma) that require follow-up. OPK is a diagnosis that should be kept in mind to avoid misdiagnosis, particularly with regard to cancer metastasis. OPK is a benign disease and invasive diagnostic procedures as well as aggressive treatment modalities should be avoided.

Figure 1: Anteroposterior, right and left hands radiograph. Multiple radio-opaque circular or ovoid dense spots with define linear sclerotic circumference, located at the proximal and distal epiphyses of phalanges and metacarpals, carpal bones and distal epiphyses of radius and ulna are noticed.

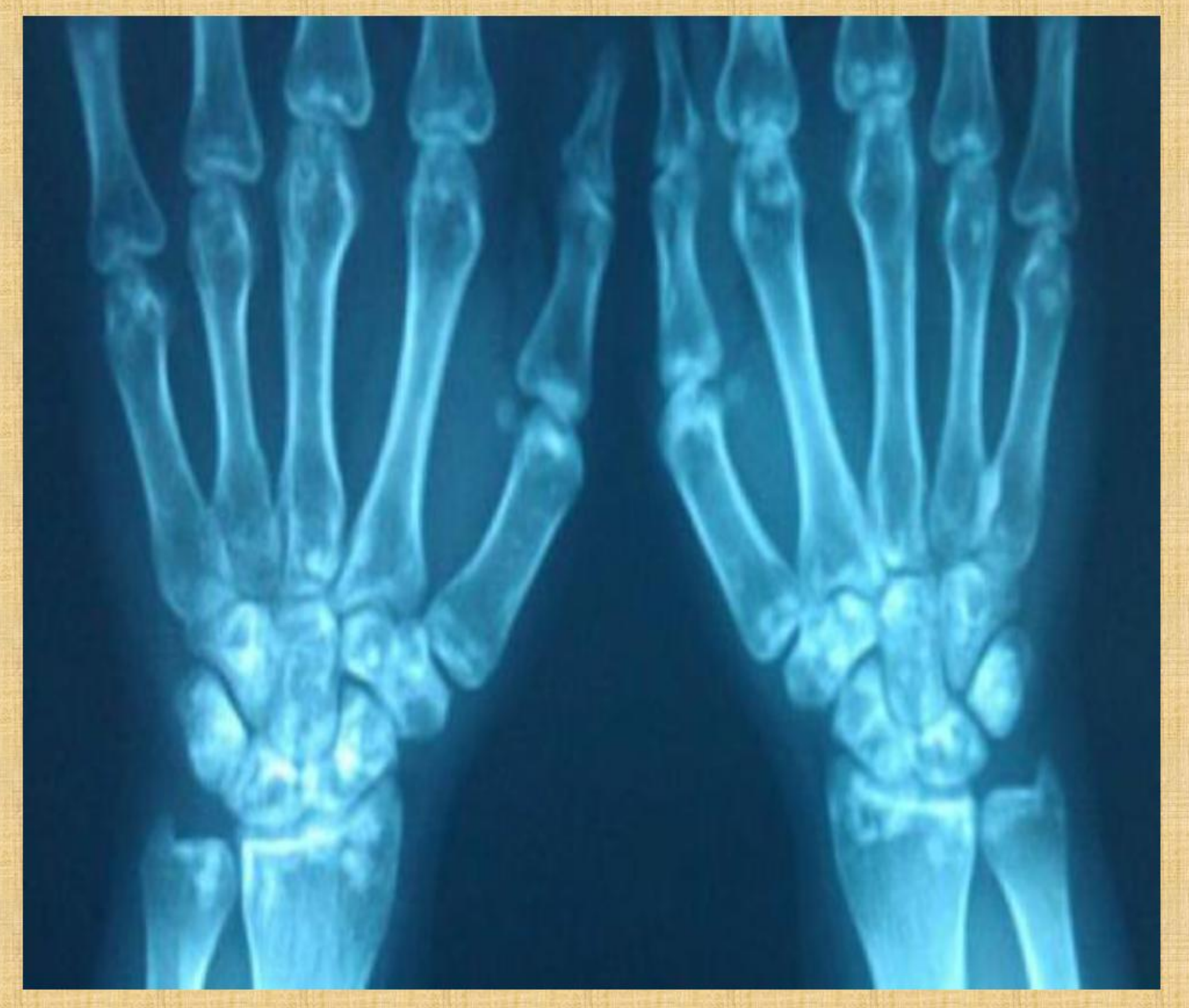

Table 1: Laboratory results of patient

\begin{tabular}{|l|l|}
\hline $\mathrm{Hb}(12.2-18.1 \mathrm{~g} / \mathrm{dl})$ & 12.2 \\
\hline Plt $(142000-424000 \mathrm{Ku} / \mathrm{L})$ & 225000 \\
\hline WBC $(4.6-10.2 \mathrm{Ku} / \mathrm{L})$ & 9.9 \\
\hline $\mathrm{Cr}(0.7-1.2 \mathrm{mg} / \mathrm{dl})$ & 0.5 \\
\hline $\mathrm{Na}(136-145 \mathrm{mmol} / \mathrm{L})$ & 136 \\
\hline $\mathrm{K}(3.5-5.1 \mathrm{mmol} / \mathrm{L})$ & 4.44 \\
\hline $\mathrm{CRP}(0-5 \mathrm{mg} / \mathrm{L})$ & 2 \\
\hline ESR $(0-22 \mathrm{~mm} / \mathrm{h})$ & 10 \\
\hline Romatoid Factor $($ positive $>20 \mathrm{IU} / \mathrm{ml})$ & 5 \\
\hline fT4 $(9.01-18.02 \mathrm{pmol} / \mathrm{L})$ & 15.15 \\
\hline fT3 $(2.63-5.70 \mathrm{pmol} / \mathrm{L})$ & 3.45 \\
\hline TSH $(0.35-4.94 \mathrm{\mu lU} / \mathrm{ml})$ & 2.36 \\
\hline ALP $(32-92 \mathrm{IU} / \mathrm{ml})$ & 69 \\
\hline PTH $(15-68.3 \mathrm{pg} / \mathrm{ml})$ & 42 \\
\hline $25-O H$ Vit D $(25-75 \mathrm{lU} / \mathrm{ml})$ & 35.7 \\
\hline Ca $(8.4-10.2 \mathrm{mg} / \mathrm{dl})$ & 9.2 \\
\hline Phosphorus $(\mathrm{mg} / \mathrm{dl} 2.5-4.6)$ & 4 \\
\hline
\end{tabular}

